\section{Case of a personal paradigm}

\section{C.R. Brand}

Personality and Individual Differences: A Natural Science Approach. By Hans J. Eysenck and Michael W. Eysenck. Plenum: 1985. Pp.424. \$29.50, £25.65.

HaNs Eysenck is Britain's best known and most cited psychologist. $\mathrm{He}$ is also the most reviled, not least for his ambitious plan (pursued now for more than 40 years) to bring the methods of natural and what he takes to be Kuhnian "normal" science to bear on human personality. For some time Eysenck has been a critic of the efforts of his indisciplined peers to write textbooks of "personality theory" books written according to a primitive calendar of saints that runs from Freud through the likes of Harry Stack Sullivan to "Ronnie" Laing, with barely a mention of the empirical efforts of Cattell, Guilford and himself. Here he is joined by his son in a courageous, readable and scholarly attempt to set the record straight.

It is a tribute to the Eysencks that even 358 pages of only occasionally selfindulgent text are barely able to encompass the many investigable contentions that Eysenck's theory has generated. As cognoscenti would expect, the Eysencks make the case that their four-and-a-half dimensions of personality - general intelligence $(g)$, neuroticism $(N)$, extraversion $(E)$, psychoticism $(P)$ and the "half" for lying $(L)$ - account for a surprisingly high percentage of empirically registered variation in human behaviour and self-reported experience; and that these dimensions have demonstrable biological bases in genetic variations, in their physiological manifestations (for example in blood group), and in experimentally distinguishable psychological mechanisms although Michael Eysenck sounds many cautionary notes about the latter possibility.

Altogether the book must appear an impressive achievement to those few humanistic or experimental (now "cognitive") psychologists who can be troubled to read it. Certainly one gasps at the amount of taxpayer's money that could have been better invested if psychological researchers had restricted their efforts of the past 20 years to the Eysencks' reasonable paradigm. Yet many will have their doubts - and not only about the startling disingenuity of the book's coverage of criminality, in the course of which the senior author (for it is surely he) interprets Passingham's sombre critique of the criminality-unconditionability link as "encouraging".

The general problem is that it is hard to something of how we are to translate into such discourse our commonplace descriptions of people as being variously endowed with properties of energy, conscience, affection and will - let alone of heart, mind, soul and spirit.

Unlike most psychological writing, this book addresses a large theme. It does so with mercifully infrequent use of words such as "sciamachy", "polythetic" and "intraception", and with a positive cornucopia (or "gallimaufry", as the Eysencks modestly prefer) of studies and experiments; and it contains many superb passages, for example on the "situationist" fad of social psychologists that we do not really have personalities. It will not, however, quite persuade anybody - at least when describing admired acquaintances - to abandon the language of the Bible and Shakespeare. That this language provides the Eysencks' only serious competition is, both fairly and unfairly, another measure of their success.

C.R. Brand is a Lecturer in the Department of Psychology, University of Edinburgh, 7 George Square, Edinburgh EH8 $9 J Z, U K$.

\section{Head for education}

\section{Andy Young}

Fundamentals of Human Neuropsychology, 2nd Edn. By Bryan Kolb and Ian Q. Whishaw. W.H. Freeman:1985. Pp.785. $\$ 27.95, £ 24.95$.

Mind and Brain: Principles of Neuropsychology. By Alberta Steinman Gilinsky. Praeger/Eurospan:1985. Pp.550. Hbk $\$ 42.95, £ 47.25 ; p b k \$ 18.95, £ 21.50$.

Brain and Mind. Edited by David A. Oakley. Methuen:1985. Pp.265. Hbk £15.95, $\$ 36 ; p b k £ 6.95$.

Two of these books (those by Gilinsky, and by Kolb and Whishaw) are general texts that cover a broad range of neuropsychological studies; the third, edited by Oakley, consists of a set of tutorial readings focused on a particular topic.

Kolb and Whishaw's Fundamentals of Human Neuropsychology, now appearing in a second edition, is one of the market leaders in its field. It is the kind of book that can convince sceptics that textbook teaching has a great deal to offer. It manages to be scholarly yet remain easily readable. If you use it to look up an unfamiliar topic, it succeeds in being informative, but gives both a clear impression that there is more to be learned and encouragement to the reader to follow things up. The authors thus manage elegantly to avoid the classic textbook failing of seeming to sum up a particular topic whilst actually only revealing a fraction of what is known. I can think of no better recommendation, and confidently expect the new edition will be as popular as its predecessor

I can't be so positive about Mind and Brain. This is a pity, because much of it is also well written and informative. The problem is that Gilinsky uses the book as a vehicle for developing a particular theory, the idea that "cognons" form the basic units of perception and cognition. In essence this is an (acknowledged) elaboration and modification of Konorski's notion of gnostic units. Cognons are claimed to account for a remarkable variety of phenomena, including letter and word recognition, face recognition, visual search, perceptual constancies, illusory contours, memory and conditioning.

All authors of textbooks must, of course, adopt some kind of theoretical stance, and it is perhaps commendable that Gilinsky's position is made so explicit. It is also unwise to dismiss new ideas just because they don't fit existing preconceptions. How we used to laugh at logogens. Nonetheless, I can't help but feel that a textbook is not the right place to discuss a theory which remains unproven.

In Oakley's collection of readings, a number of distinguished contributors discuss what is known about various aspects of the relation between brain and mind. The appearance of the book at this time is appropriate, because neuropsychologists now have the confidence to tackle such exciting and fundamental questions. This is an accessible anthology which students will find helps them get to grips with some of the most taxing neuropsychological questions.

Andy Young is a Lecturer in the Department of Psychology, University of Lancaster, Lancaster $L A 14 Y F$, UK 